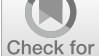

Check for

updates

Cite as

Nano-Micro Lett.

(2021) $13: 162$

Received: 12 May 2021

Accepted: 11 July 2021

Published online: 2 August 2021

(C) The Author(s) 2021

\section{A Healable and Mechanically Enhanced Composite with Segregated Conductive Network Structure for High-Efficient Electromagnetic Interference Shielding}

\author{
Ting Wang ${ }^{1}$, Wei-Wei Kong ${ }^{1}$, Wan-Cheng $\mathrm{Yu}^{1}$, Jie-Feng Gao ${ }^{2}$, Kun Dai ${ }^{3}$, \\ Ding-Xiang Yan ${ }^{1,4}$, Zhong-Ming $\mathrm{Li}^{1}{ }^{凶}$
}

\title{
HIGHLIGHTS
}

- The cationic waterborne polyurethanes microspheres with Diels-Alder bonds were synthesized for the first time.

- The electrostatic attraction not only endows the composite with segregated structure to gain high electromagnetic-interference shielding effectiveness, but also greatly enhances mechanical properties.

- Efficient healing property was realized under heating environment.

ABSTRACT It is still challenging for conductive polymer composite-based electromagnetic interference (EMI) shielding materials to achieve long-term stability while maintaining high EMI shielding effectiveness (EMI SE), especially undergoing external mechanical stimuli, such as scratches or large deformations. Herein, an electrostatic assembly strategy is adopted to design a healable and segregated carbon nanotube (CNT)/graphene oxide (GO)/polyurethane (PU) composite with excellent and reliable EMI SE, even bearing complex mechanical condition. The negatively charged CNT/GO hybrid is facilely adsorbed on the surface of positively charged PU microsphere to motivate formation of segregated conductive networks in CNT/GO/PU composite, establishing a high EMI SE of $52.7 \mathrm{~dB}$ at only $10 \mathrm{wt} \% \mathrm{CNT} / \mathrm{GO}$ loading. The

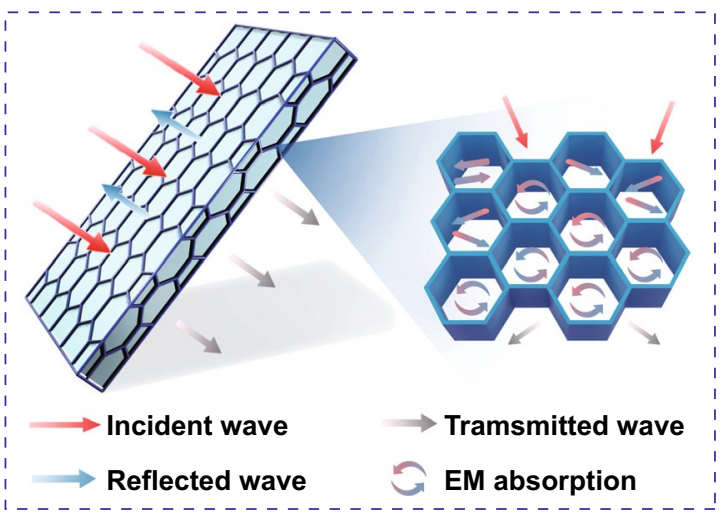
Diels-Alder bonds in PU microsphere endow the CNT/GO/PU composite suffering three cutting/healing cycles with EMI SE retention up to $90 \%$. Additionally, the electrostatic attraction between CNT/GO hybrid and PU microsphere helps to strong interfacial bonding in the composite, resulting in high tensile strength of $43.1 \mathrm{MPa}$ and elongation at break of $626 \%$. The healing efficiency of elongation at break achieves $95 \%$ when the composite endured three cutting/healing cycles. This work demonstrates a novel strategy for developing segregated EMI shielding composite with healable features and excellent mechanical performance and shows great potential in the durable and high precision electrical instruments.

KEYWORDS Electrostatic attraction; Healable; EMI shielding; Diels-Alder reaction

Ding-Xiang Yan, yandingxiang@scu.edu.cn; Zhong-Ming Li, zmli@scu.edu.cn

1 College of Polymer Science and Engineering, State Key Laboratory of Polymer Materials Engineering, Sichuan University, Chengdu 610065, People's Republic of China

2 The College of Chemistry and Chemical Engineering, Yangzhou University, Yangzhou 225009, People's Republic of China

3 School of Materials Science and Engineering, Zhengzhou University, Zhengzhou 450001, People's Republic of China

4 School of Aeronautics and Astronautics, Sichuan University, Chengdu 610065, People's Republic of China 


\section{Introduction}

With the development of electronics technology, especially the advent of $5 \mathrm{G}$ era, electromagnetic interference (EMI) shielding materials are increasingly required to prevent the electronic devices and human bodies from suffering intense electromagnetic radiation [1-3]. Considerable efforts have been devoted to fabricate conductive polymer composites (CPCs)-based EMI shielding materials due to the lightweight, easy processibility, low cost, corrosion resistance, etc. [4-6]. Normally, plenty of conductive fillers are necessary to obtain outstanding EMI SE in CPCs, which may result in low economic affordability, inferior flexibility and low processability [7-9]. Current researches mainly focus on structural design to improve conductive network to achieve high EMI SE [10-13]. Segregated structure, with conductive fillers confined located at interfaces of polymer regions, is considered to significantly increase the effective concentration of conductive fillers to construct perfect conductive network in CPCs [14-18]. Numerous works including our previous works have achieved outstanding EMI SE in CPCs with segregated structure [19-22], whereas the accompanying conductive filler-polymer region interfaces and interfacial crack would cause degraded mechanical properties. The simultaneous achievement of EMI SE and mechanical properties in segregated CPCs promises their great potential as advanced shielding materials for various applications including aerospace and smart electronic devices.

Over the practical situations, EMI shielding CPCs would inevitably generate micronotches or breaks when suffering external mechanical stimulus such as fatigue, abrasion and impact, which may result in performance degradation and even catastrophic failure of the devices [23-27]. Recently, many efforts have been done to develop healable EMI shielding CPCs with the polymer matrix owning reversible bonds [28]. For instance, a healable polyurethane with disulfide bonds was filled with carbon nanotube (CNT)/graphene oxide (GO)/ $/ \mathrm{MoS}_{2} / \mathrm{Fe}_{3} \mathrm{O}_{4}$ nanoparticles, and the resultant composite exhibited healing efficiency of $70 \%$ in mechanical properties and nearly unaltered EMI SE post-healed for $24 \mathrm{~h}$ at room temperature [29]. Contacting the cracked polyacrylamide/cellulose nanofiber/CNT hydrogel for a week could recover the EMI SE with high retention of $\sim 96 \%$ [30]. In the healing system, reversible Diels-Alder (DA) reaction is one such highly viable mechanism to achieve healing behavior in polymers ascribes to its simple process, minimal side reactions, highly efficient reversibility, moderate sensitivity to temperature and dynamic cross-linking structure [31]. It is worth noting that though considerable healable effects have been achieved, the reported EMI shielding CPCs mainly contained randomly distributed conductive fillers, while few works report healable CPCs containing segregated conductive networks. This is attributed to the challenged acquisition of polymer granules with healable features. The development of healable and segregated CPCs is of great significance to increase the lifespan and sustainability of high-performance EMI shielding devices. In our recent work, a healable polyurethane was made by external emulsification and used as a matrix to obtain the healable and segregated EMI shielding composite [32]. The composite at $7 \mathrm{wt} \%$ CNT content shows EMI SE of $41.2 \mathrm{~dB}$ and undesirable mechanical properties with stress of $\sim 15.6 \mathrm{MPa}$ and low elongation at break of $\sim 340 \%$, while the composite even cannot be formed when the CNT loading up to $10 \mathrm{wt} \%$.

Herein, the cationic waterborne polyurethanes microspheres with DA bonds (denoted as CPA microspheres) were synthesized for the first time to adsorb anionic CNT/ GO hybrid via electrostatic attraction to help the construction of segregated conductive network in the resultant CNT/GO/CPA composite. The healable EMI shielding composite was obtained by taking the advantage of electrostatic assembling between the negatively charged carbon nanotube/graphene oxide and positively charged CPA. The electrostatic attraction not only endows the composite with segregated structure to gain high EMI SE, but also greatly enhances mechanical properties. The composite with $7 \mathrm{wt} \%$ filler loading owns high EMI SE of $46.0 \mathrm{~dB}$ and excellent mechanical property with stress of $\sim 32.5 \mathrm{MPa}$ and elongation at break of $\sim 431 \%$. And the composite still exhibits sufficient flexibility even at $10 \mathrm{wt} \%$ filler loading with elongation at break up to $\sim 400 \%$. Moreover, the composite could recover the EMI shielding and mechanical performances on subjecting to the severe mechanical damages due to the DA bonds. The CNT/GO/CPA composites could be repeatedly healed with $90 \%$ retention in EMI SE and 95\% healing efficiency in mechanical properties. Such a unique CNT/GO/CPA composite helps to improve the long-term stability of EMI shielding materials in actual application. 


\section{Experimental Section}

\subsection{Materials}

CNTs (NC 7000 series) with surface area of 250-300 $\mathrm{m}^{2} \mathrm{~g}^{-1}$, average diameter of $9.5 \mathrm{~nm}$, average length of $1.5 \mu \mathrm{m}$ were supplied by Nanocyl S.A., Belgium. Isophorone diisocyanate (IPDI), glycerol 1,2-carbonate, furfurylamine, dibutyltin dilaurate (DBTDL), 1,4-butanediol (BDO) and 1,1'-(methylene-di-4,1-phenylene)-bismaleimide (BMI) were purchased from Aladdin, China. The chemicals were used for subsequent reactions without any treatment. Polytetramethylene ether glycol (PTMG) $\left(\mathrm{Mn}=2000 \mathrm{~g} \mathrm{~mol}^{-1}\right)$ was obtained from Aladdin and placed in a vacuum oven at $110{ }^{\circ} \mathrm{C}$ for $2 \mathrm{~h}$ to remove water prior use. Methyldiethanolamine (MDEA) and Methyl ethyl ketone (MEK) were provided by Kelong Chemical Co., Ltd., China.

\subsection{Synthesis of Cationic Waterborne Polyurethane with DA Bonds (CPA)}

The synthesis process of CPA is shown in Fig. S1. Glycerol 1,2-carbonate $(4.28 \mathrm{~mL})$ and furfurylamine $(4.46 \mathrm{~mL})$ were mixed in a round-bottom flask. The mixture was stirred and heated at $60{ }^{\circ} \mathrm{C}$ for $3 \mathrm{~h}$ in an oil bath to obtain the Diol. Then Diol (0.65 g), IPDI (7.5 g), PTMG (10.0 g) were placed in the round-bottom flask. After the addition of $5 \mu \mathrm{L}$ DBTDL and a moderate amount of MEK, the solution was heated at $60{ }^{\circ} \mathrm{C}$ for $2 \mathrm{~h}$ with homogeneous stir. $1.4 \mathrm{~g}$ MDEA was diluted with MEK and added dropwise into the above mixture. Subsequently, the mixture was reacted for $2 \mathrm{~h}$ to get the -NCO groups terminated oligomer. To extend the intermediated products, a precalculated amount of BDO $(0.5 \mathrm{~g})$ was added slowly to the reaction solution. After $1 \mathrm{~h}$ of chain extension reaction, BMI (1.5 g) was added and fully dissolved in the solution and reacted for another $6 \mathrm{~h}$ to generate DA bonds. During the reaction process, MEK was added occasionally to prevent excessive viscosity of the reaction solution. After that, the reaction product and acetic acid $(0.8 \mathrm{~g})$ were mixed at $40{ }^{\circ} \mathrm{C}$ for $30 \mathrm{~min}$ with continuous stirring, which was aimed to neutralize the ionic centers of MDEA. To get the CPA emulsion, the deionized water was added to the obtained mixture under vigorous stirring for $1 \mathrm{~h}$. Finally, the MEK was removed with rotary evaporator.
The ultimate CPA emulsion was cream yellow with a solid content of $25 \mathrm{wt} \%$.

\subsection{Preparation of the CNT/GO/CPA Composite}

The fabrication process of the CNT/GO/CPA composite is schematically illustrated in Fig. 1 The aqueous suspension of $\mathrm{CNT} / \mathrm{GO}(\mathrm{GO} / \mathrm{CNT}=1: 5)$ with negative charge was firstly prepared. Then, the CNT/GO suspension was quantitatively added into the positively charged CPA emulsion with vigorous stirring. The CNT/GO/CPA coagulation was obtained by electrostatic self-assembly, following with suction filtration and freeze-dried process to get the CNT/GO/CPA complex granules. The CNT/GO/CPA composite was fabricated by compression molding of the CNT/GO/CPA complex granules at $130{ }^{\circ} \mathrm{C}$ for $10 \mathrm{~min}$. The ultimate composites were named as CG@CPA-x, where x represents the weight content of CNT/GO hybrid in the composite. The bulk CPA film was also prepared for comparison, under the same condition without the addition of CNT/GO hybrid.

\subsection{Characterization}

Zeta potential measurements were determined with a Zetasizer Nano ZS90 instrument (Malvern, UK). The size distribution of CPA emulsion was measured using Mastersizer 2000 laser particle size analyzer. The existence of quaternary ammonium salt in CPA microspheres was proved by an X-ray photoelectron spectroscopy (XPS, XSAM800, Shimadzu-Kratos Ltd., Japan). Fourier-transform infrared

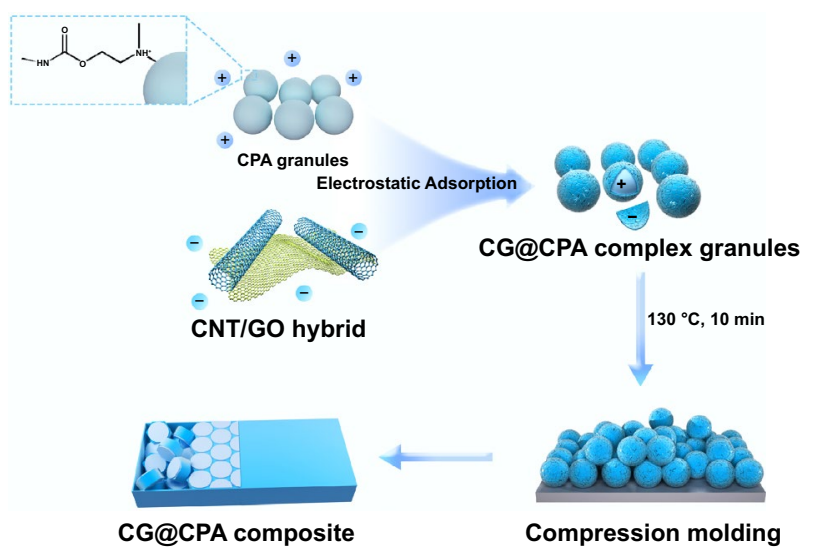

Fig. 1 Schematic diagram of the fabrication process for CG@CPA composite 
(FTIR) spectroscopy (Nicolet 6700, Thermal Scientific, USA) was used to record the chemical structure of the composite. The electrical conductivities of the composites were conducted on an RTS-9 four-point probe meter (Guangzhou Four-Point Probe Technology Co., Ltd., China). Mechanical properties were measured on a universal tester (Model 5576, Instron Instruments, USA) with a crosshead speed of $50 \mathrm{~mm} \mathrm{~min}^{-1}$ and gauge length of $20 \mathrm{~mm}$. At least five dumbbell-shaped specimens with $4.0 \mathrm{~mm}$ width and $50.0 \mathrm{~mm}$ length were tested for each group. Optical microscope (OM, Olympus Co., Tokyo, Japan) equipped with a heating stage (CSS450, Linkam Scientific instruments, UK) was used to monitor the healing process of the crack among the specimen. The temperature rose to $130{ }^{\circ} \mathrm{C}$ for $5 \mathrm{~min}$ with a heating rate of $10{ }^{\circ} \mathrm{C} \mathrm{min}{ }^{-1}$. And taking micrographs to record the healing process with time intervals of $30 \mathrm{~s}$. Morphology and microstructures were observed with a scanning electron microscope (SEM; Inspect-F, FEI, USA) at an acceleration voltage of $5 \mathrm{kV}$ and a FEI Tecnai F20 transmission electron microscope (TEM) at an acceleration voltage

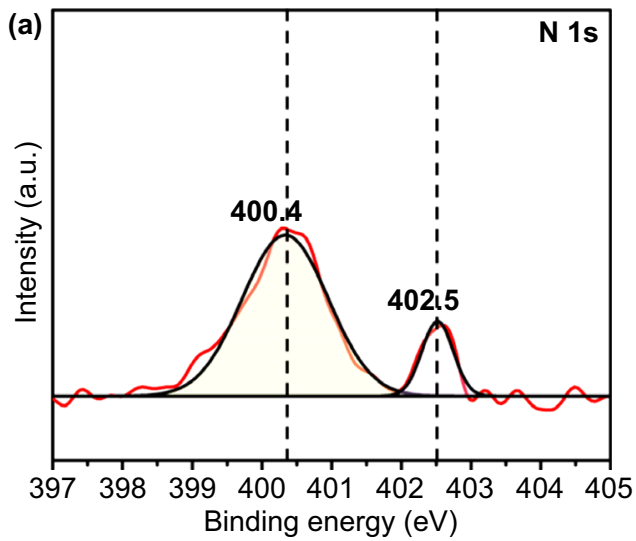

(c) 50

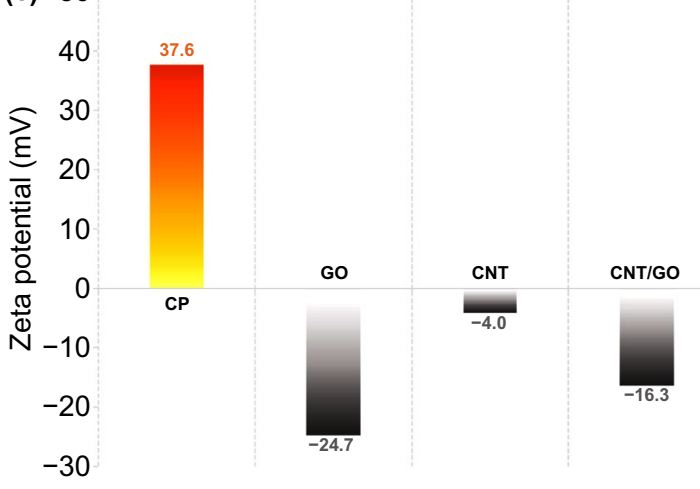

of $200 \mathrm{kV}$. For SEM observation, the specimens were soaked into the liquid nitrogen for $30 \mathrm{~min}$ and cryo-fractured. All of the specimens were coated a thin layer of gold before SEM test. For TEM observation, CG@CPA composite specimens were cryo-microtomed using a Leica EM UC6 equipment to get the ultrathin cryo-sections of 50 to $100 \mathrm{~nm}$ thickness, which were collected and directly supported on a copper grid. The circular samples with $12.0 \mathrm{~mm}$ diameter and $2.0 \mathrm{~mm}$ thickness were used to test EMI SE on an Agilent N5230 vector network analyzer within 8.2-12.4 GHz. And the detailed calculate formulas of $\mathrm{SE}_{\mathrm{T}}, \mathrm{SE}_{\mathrm{R}}$ and $\mathrm{SE}_{\mathrm{A}}$ were shown in Supporting Information (SI).

\section{Results and Discussion}

\subsection{Structure and Composition Characteristics}

The quaternary ammonium ions in the CPA are necessary for the electrostatic self-assembly. To demonstrate the

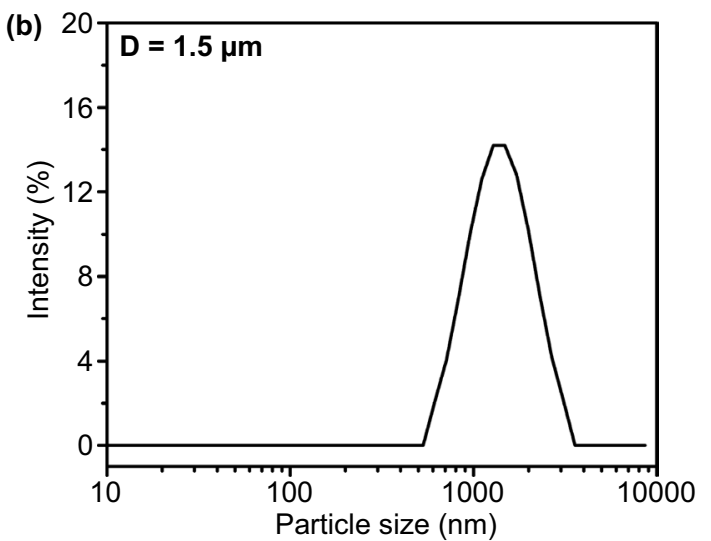

(d)

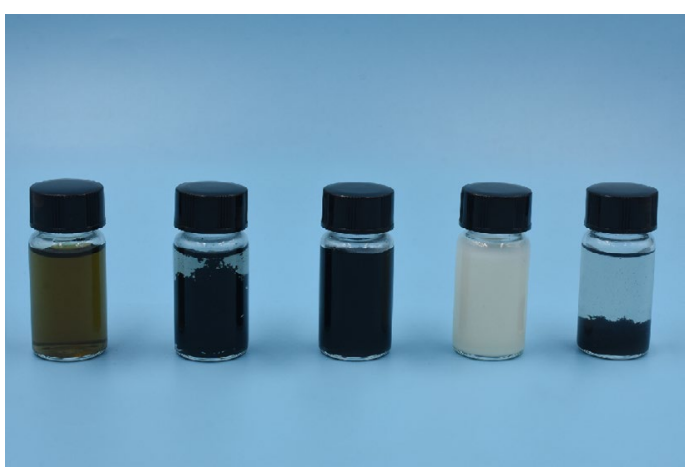

Fig. 2 a XPS survey spectra of CPA. b Size and distribution of CPA particles. c Zeta potential of CPA, GO, CNT and CNT/GO aqueous dispersions. d Digital picture of GO, CNT, CNT/GO, CPA and CG@CPA aqueous dispersions (from left to right in the picture) after being placed for $12 \mathrm{~h}$ 
existence of quaternary ammonium ions, XPS spectra of CPA were carried out, as shown in Fig. 2a. In the $\mathrm{N} 1 s$ spectrum, two peaks at 400.4 and $402.5 \mathrm{eV}$ emerged which are related to $\mathrm{C}-\mathrm{N}$ bond of urethane and cationic $-\mathrm{NH}\left(\mathrm{CH}_{3}\right)_{2}{ }^{+}$ from MDEA molecular chain respectively, indicating the successful preparation of cationic waterborne polyurethane. The FTIR spectroscopy (Fig. S2) further demonstrates the chemical structure of the CPA and relevant statement is shown in SI. The average size of CPA microspheres was $1.5 \mu \mathrm{m}$ (Fig. 2b). The Zeta potential test can not only measure the possibility of electrostatic adsorption, but also evaluate the stability of the dispersion. MDEA converted to quaternary ammonium salt on the CPA molecular chain through acid-base neutralization reaction, endowing the CPA microspheres with the Zeta potential value of $+37.6 \mathrm{mV}$ (Fig. 2c). The higher absolute value of Zeta potential illustrates that abundant electrostatic repulsive energy is presented on the surface of CPA specimens, demonstrating better physical stability [33]. The Zeta potential values for the GO, CNT, CNT/GO aqueous dispersion are $-24.7,-4.0,-16.3$, respectively, indicating that a small amount of GO can help CNT to be uniformly dispersed in water due to the $\pi-\pi$ conjugation between them [34-36]. The CNT/GO dispersion was added into the CPA emulsion with homogeneous stirred. The positive charged surfaces of the CPA particles were partly neutralized by the negative charge of the hybrid filler, thus the potential drops. Figure $2 \mathrm{~d}$ shows the dispersion condition of the GO, CNT, CNT/GO hybrid, CPA microspheres and CG@CPA complex in deionized water (from left to right) after settled for $12 \mathrm{~h}$. Significantly, the CNT/ $\mathrm{GO}$ are continuously assembled on the CPA microspheres by electrostatic attraction and further settle completely.

Figure 3a shows that the CG@CPA powder is composed by numerous spherical complex granules. In the magnified SEM image (Fig. 3b), numerous CNT/GO hybrid are compactly wrapped on the surface of the CPA granules, which is conducive to the construction of efficient conductive networks in the final CG@CPA composites. The CG@CPA powder was further hot-pressed to prepare CG@CPA composites, and the internal morphology is shown in Fig. 3c, d.
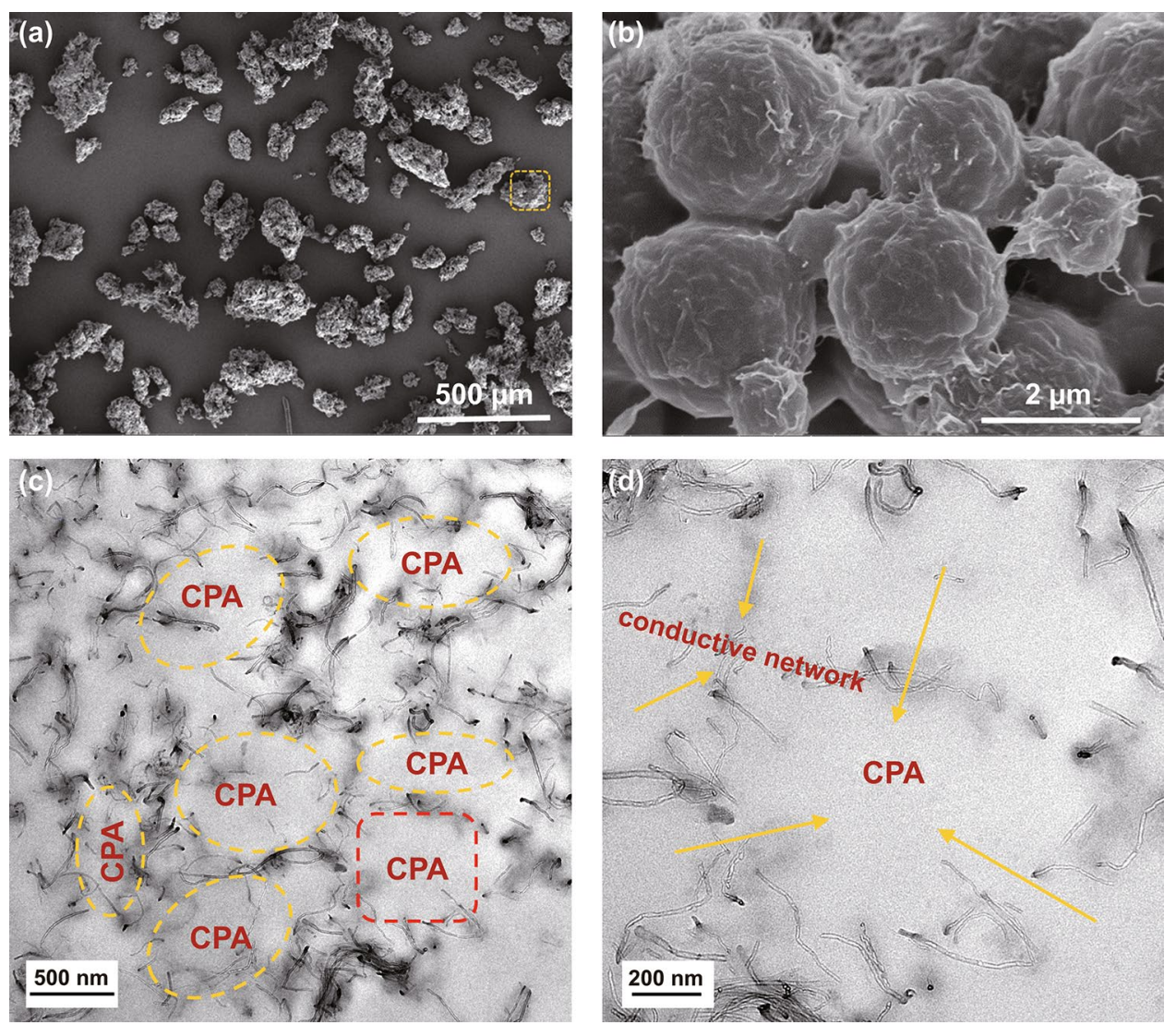

Fig. 3 a, b SEM images of the CG@CPA-3 particles. c, d TEM images of the CG@CPA-3 composite 
As expected, conductive fillers are all selectively located at the interfaces of the CPA domain, forming a well-defined and interconnected network. Encouragingly, the unique 3D conductive network helps to improve the electrical and EMI shielding capacities.

\subsection{Electrical and EMI Shielding Performances of CG@CPA Composite}

Figure 4a reveals the electrical conductivity of the CG@CPA composite. Obviously, the electrical conductivity improves with the increasing CNT/GO content. The CG@CPA-1 exhibits the conductivity of $5.0 \mathrm{~S} \mathrm{~m}^{-1}$, which already exceed the required value of commercial EMI shielding materials $\left(1.0 \mathrm{~S} \mathrm{~m}^{-1}\right)[37,38]$. The electrical conductivity of the CG@ CPA-10 could attain to $52.0 \mathrm{~S} \mathrm{~m}^{-1}$ due to the highly efficient segregated conductive network. The desirable electrical
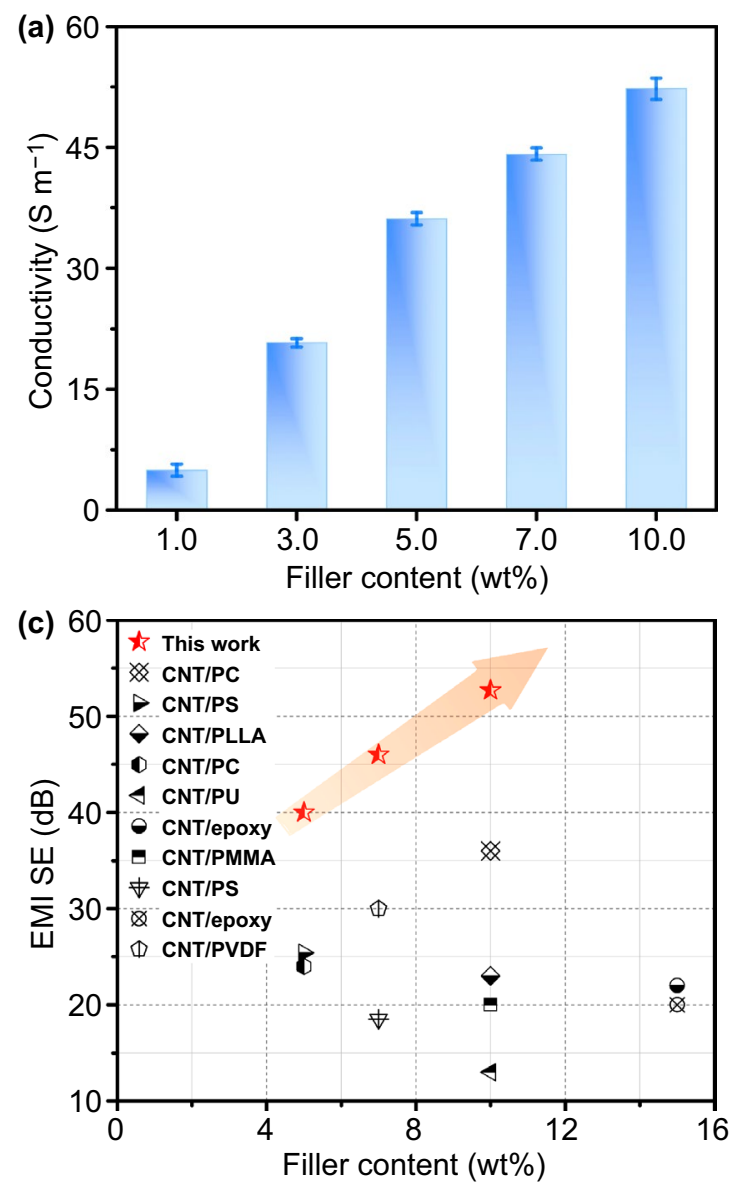

conductivity is an essential prerequisite for the CG@CPA composite to obtain outstanding EMI shielding performance [39-41]. Figure 4b reveals EMI SE of CG@CPA composites in the frequency range of $8.2-12.4 \mathrm{GHz}$ (X-band). As the CNT/GO content increases, the EMI SE of the composite apparently enhances, which is consistent with the trend of electrical conductivity. With higher CNT/GO loading, more free electrons will be generated to interact with the incoming EM waves and thus improve the EMI SE. CG@ CPA-3 exhibits the EMI SE of $34.1 \mathrm{~dB}$, far surpassing the target value of the commercially applicable EMI shielding materials (20 dB) [42]. CG@CPA-10 obtains the maximum EMI SE of $52.7 \mathrm{~dB}$, which could block $99.9995 \%$ incident electromagnetic wave. The EMI SE (34.1 dB) of the CG@ CPA-3 composite is also superior to $27.7 \mathrm{~dB}$ for our previously reported segregated CNT/PU composite by ball milling (for CNT@PUDA-3), indicating that the electrostatic attraction has an auxiliary effect on the perfection of the
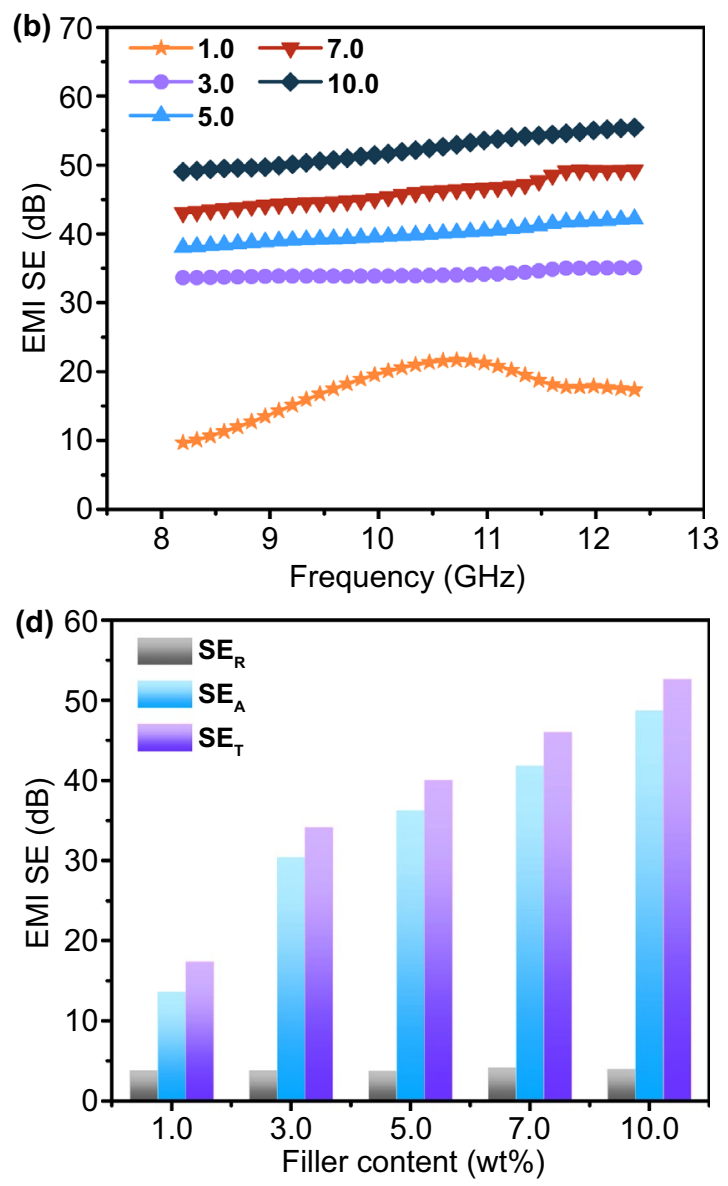

Fig. 4 a Electrical conductivity b EMI SE of the CG@CPA composite with various CNT/GO content. c Comparison of EMI SE of CG@CPA composite and other reported composites d Comparison on $\mathrm{SE}_{T}, \mathrm{SE}_{\mathrm{A}}$ and $\mathrm{SE}_{R}$ of $\mathrm{CG} @ \mathrm{CPA}$ composites 
segregated conductive network. Moreover, the achieved high EMI SE in the CG@CPA composite is competitively compared with most previously reported composites, as summarized in Fig. 4c and Table S1 [43-52].

To better clarify the shielding mechanism for the CG@ CPA composite, $\mathrm{SE}_{\mathrm{R}}$ and $\mathrm{SE}_{\mathrm{A}}$ calculated from the measured scattering parameters are summarized in Fig. 4d. It can be obviously seen that $\mathrm{SE}_{A}$ shows almost the same variation tendency and contributes overwhelmingly with $\mathrm{SE}_{T}$ (EMI SE), whereas $\mathrm{SE}_{R}$ hardly changes, regardless of CNT/GO hybrid loading, demonstrating the absorption dominated EMI shielding mechanism. For instance, $\mathrm{SE}_{R}$, $\mathrm{SE}_{A}$ and $\mathrm{SE}_{T}$ of CG@CPA-10 are 4.0, 48.7 and $52.7 \mathrm{~dB}$, manifesting that the $\mathrm{SE}_{A}$ makes a large proportion of $92 \%$ contribution to the $\mathrm{SE}_{T}$. The $\mathrm{SE}_{A}$ dominated mechanism mainly originated the well-defined segregated 3D conductive network (Fig. 5). The CNT/GO is located at the interfaces of the CPA domain to form a honeycomb-like EMI shielding cage. The CNT/GO conductive layer could generate mass interfaces to enhance reflect and scatter EM waves, thereby extending the propagation path of the EM waves and further attenuating electromagnetic energy. And the trapped EM waves could hardly escape from the compact core-shell structure before dissipate in the form of thermal energy.

\subsection{Mechanical Properties of the CG@CPA Composite}

The successful construction of the segregated structure endows the CG@CPA composite with a high EMI SE. In addition, the CNT/GO hybrid firmly attached to the CPA particles through electrostatic attraction, forming the robust composite with enhanced interface bonding. The

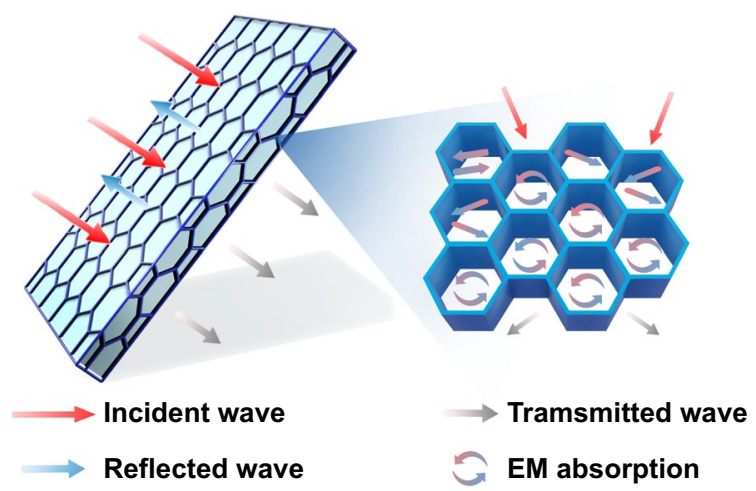

Fig. 5 EMI shielding mechanism of the CG@CPA composite detailed quantified mechanical properties are shown in the stress-strain curves (Fig. 6a, b). The pure CPA represents satisfactory flexibility with a relatively low stress of $\sim 17.5 \mathrm{MPa}$ and an elongation at break (EB) of $\sim 700 \%$. As the CNT/GO content increases, the Young's modulus of the CG@CPA composite gradually rises on account of the stiff hybrid filler inside the composite. Meanwhile, the stress rises sharply to $43.1 \mathrm{MPa}$ of CG@CPA-3 due to the efficient load transfer from the CPA to the compact CNT/ GO network. Moreover, the CG@CPA composite still shows superior mechanical properties that surpass other reported composites with similar structures [53-55], especially for the CG@CPA-3 with high stress and high EB ( 626\%). And the CG@CPA-7 exhibits EB of 431\% and stress of $\sim 32.5 \mathrm{MPa}$, which simultaneously increases the strength and EB compared to our previous CNT@PUDA-7 (340\%, $\sim 15.6 \mathrm{MPa})$. Besides, the robust CG@CPA-10 remains sufficient flexibility with EB of $\sim 400 \%$ and stress of $\sim 30.5 \mathrm{MPa}$, which is more than enough for the application in flexible electronic devices [56]. As shown in Fig. 6c-e, the CG@ CPA-10 even can be arbitrarily bent or folded even, showing great flexibility while the CNT@PUDA-10 cannot be efficiently prepared. Obviously, the electrostatic attraction in the segregated CNT/GO/CPA composite makes the interfaces connection tighter and solves the interface defects between the matrix and the filler in conventional segregated CPCs, contributing to enhanced mechanical properties.

\subsection{Thermal-Driven Reversibility of CG@CPA Composite}

While having excellent EMI shielding and mechanical properties, the CG@CPA composite also owns healable function based on the DA bond. To test the healing behavior in terms of electrical and EMI shielding performances, original CG@CPA-10 was damaged into two halves. Then, the two parts were compacted together to treat at $130{ }^{\circ} \mathrm{C}$ for $10 \mathrm{~min}$ and then put at $60{ }^{\circ} \mathrm{C}$ for $2 \mathrm{~h}$ to measure the EMI SE again. The electrical conductivity and EMI SE varied with healing cycles are shown in Fig. 7a, b. For convenience, the first, second and third cutting/healing cycles of the CG@CPA-10 that occur at the same location are called $1 \mathrm{HC}, 2 \mathrm{HC}$ and $3 \mathrm{HC}$, respectively. The electrical conductivity of $1 \mathrm{HC}$ is $51.5 \mathrm{~S} \mathrm{~m}^{-1}$, which is only $1.0 \%$ lower than the original value $\left(52.0 \mathrm{~S} \mathrm{~m}^{-1}\right)$. Encouragingly, electrical conductivity of 3 

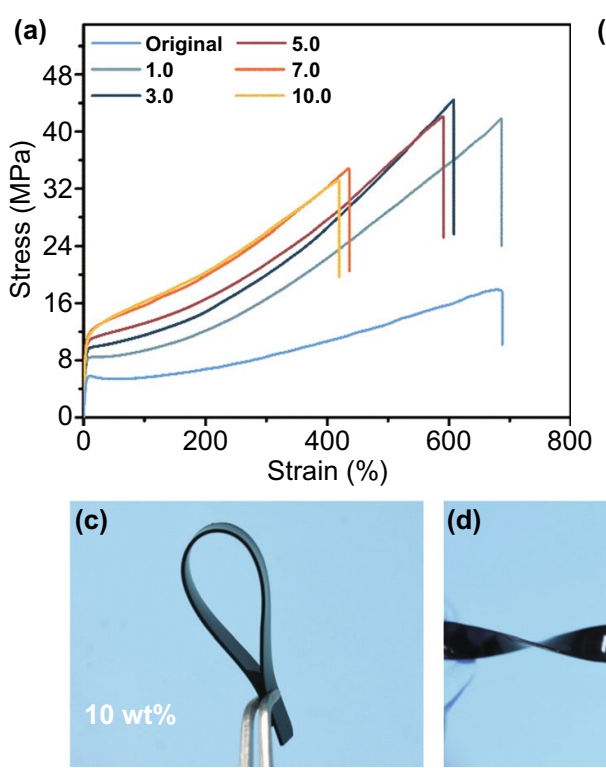

(d)

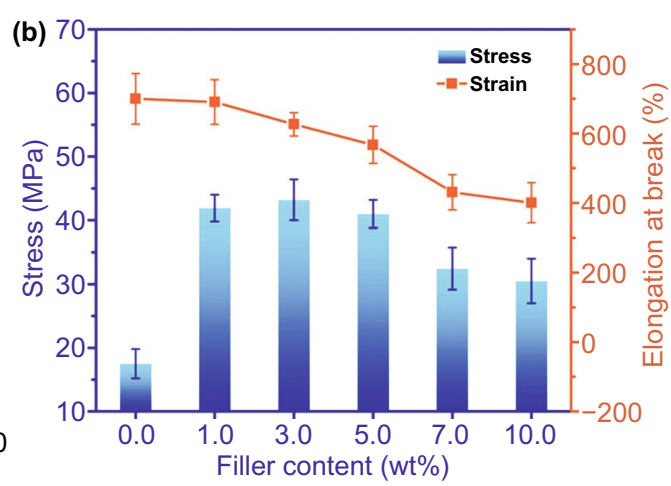

I.

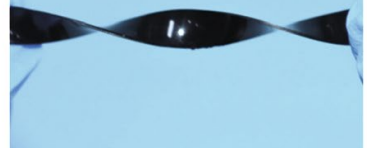

(e)

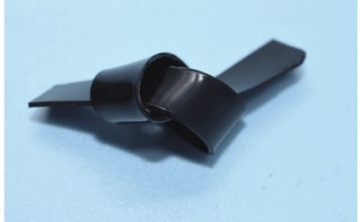

Fig. 6 a Stress-strain curves and $\mathbf{b}$ average stress and elongation at break of CG@CPA composites with various CNT/GO hybrid loadings. c-e Photographs of the CG@CPA-10 with great flexibility

(a)

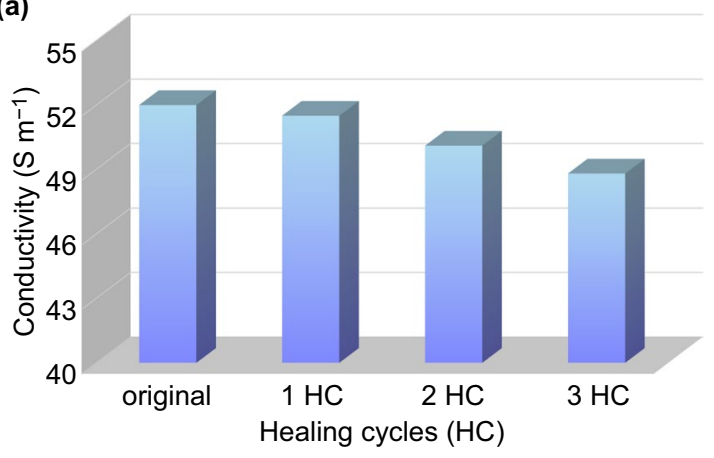

(c)

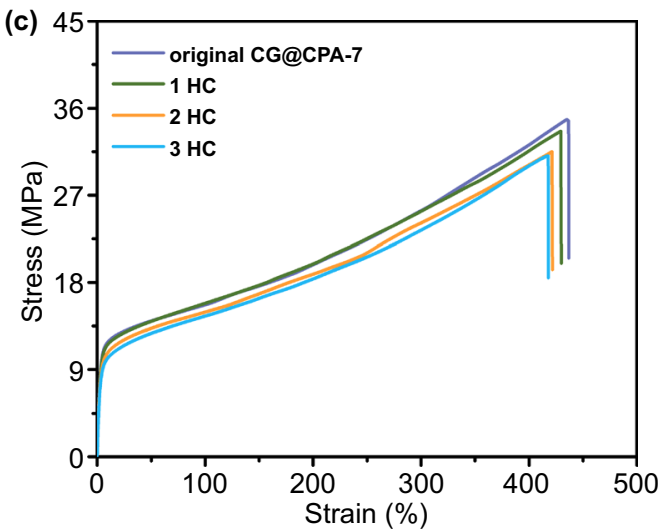

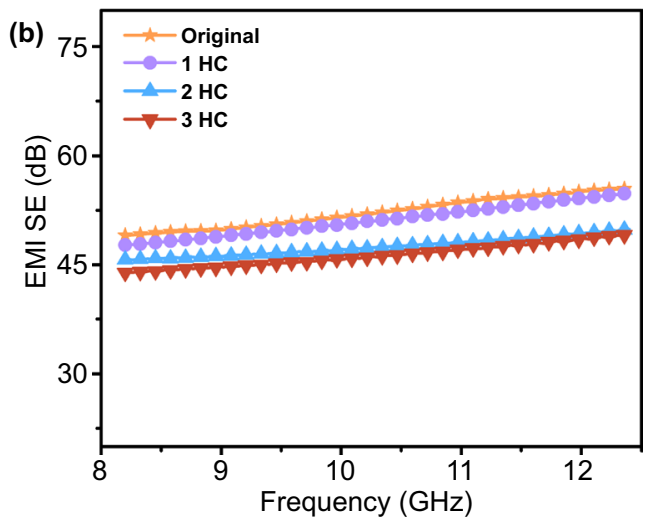

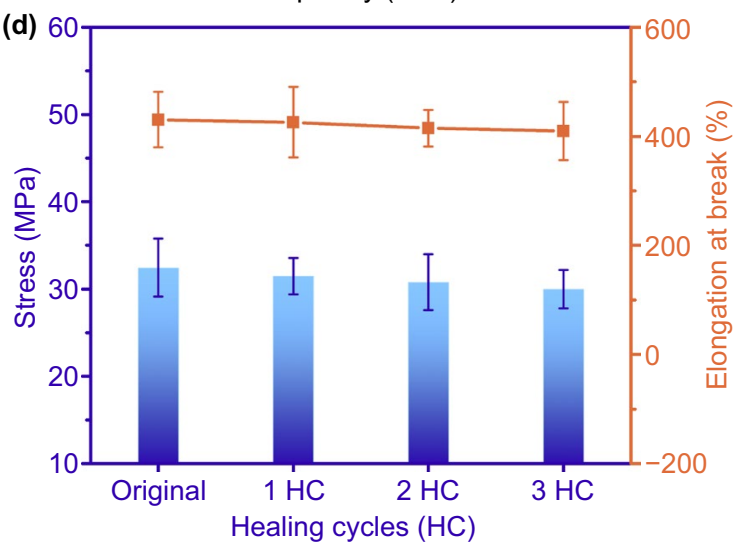

Fig. 7 a Electrical conductivity and b EMI SE versus the healing cycles of the CG@CPA-10. c Stress-strain curves and d average stress and elongation at break of initial and healed CG@CPA-7 
$\mathrm{HC}\left(\sim 48.8 \mathrm{~S} \mathrm{~m}^{-1}\right)$ still maintains a high retention of $94 \%$, suggesting that CG@CPA composite possesses eminent repeatable repair capability. The EMI shielding performance of CG@CPA composite can also be repeatedly healed. For instance, the EMI SE of the $1 \mathrm{HC}$ is $51.1 \mathrm{~dB}$ with only slight decreases compared to initial value $(52.7 \mathrm{~dB})$. And the recovery efficiency in EMI SE (the ratio of EMI SE before and after healing) of the $3 \mathrm{HC}(47.3 \mathrm{~dB})$ can keep $90 \%$. From the above results, it can be inferred that the segregated conductive pathway at the fracture interfaces of the composite is well reconstructed after the repeated healing process, achieving high healing efficiencies on electrical and EMI shielding performances.

The repeatable repair ability of CG@CPA composite is also adapted to mechanical properties. As shown in Fig. S3, the CG@CPA-7 is cut in half. And it can lift a $50 \mathrm{~g}$ weight without fracture or regeneration of scars after healing process. The more intuitive healing process was recorded in Video S1. Put the fractures of the broken CG@CPA-7 together on a hot stage with $130^{\circ} \mathrm{C}$ for $5 \mathrm{~min}$ and then continue to treat them at $60{ }^{\circ} \mathrm{C}$ for $2 \mathrm{~min}$. The sample is healed after the above treatment and not broken when suffer from the tension of hands, which further illustrate the successful recovery of mechanical properties. To quantitatively evaluate the healing ability, the tensile measurement was used to test mechanical properties of repaired and the virgin specimens. The healing efficiencies were calculated by ratio of $\mathrm{EB}$ of the healed composites to the initial samples. The mechanical properties of the CG@CPA-7 with different cutting/healing cycles are shown in Fig. 7c, d. The mechanical curves of the $1 \mathrm{HC}$ and the original sample basically coincide, indicating that the mechanical properties have been efficiently restored. Additionally, the composite can be healed repeatedly. For example, even $3 \mathrm{HC}$ has a similar EB of $\sim 410 \%$ compared to $\sim 431 \%$ of the virgin one and displays a very close tensile strength $(\sim 30.0 \mathrm{MPa})$ to the initial value (32.5 MPa). The healing efficiencies for $1 \mathrm{HC}$, $2 \mathrm{HC}$ and $3 \mathrm{HC}$ are $\sim 99 \%, \sim 96 \%$ and $\sim 95 \%$, respectively, demonstrating that CG@CPA composite can be repaired for multiple times with only a weak reduction in the healing efficiency. And the healing efficiencies of the EB are higher than the previously reported similar composite [26, 57-59]. The CG@CPA composite with superior and healable mechanical properties has significant potential to apply in the robust EMI shielding instrument.

The reversibility of DA reaction in CPA was demonstrated through FTIR spectroscopy in terms of a heating/cooling procedure (Fig. 8). The characteristic peak at $1772 \mathrm{~cm}^{-1}$ corresponds to the DA adduct which is produced by the forward DA reaction. The peak of maleimide obtained through the reverse DA reaction of CPA at $130{ }^{\circ} \mathrm{C}$ should be located at $696 \mathrm{~cm}^{-1}$ [60]. The CPA curve appears the peak of $1772 \mathrm{~cm}^{-1}$ but no peak of $696 \mathrm{~cm}^{-1}$, showing that maleimide successfully participated in the DA reaction. Nevertheless, the peak of $1772 \mathrm{~cm}^{-1}$ disappeared and $696 \mathrm{~cm}^{-1}$ emerged when the original CPA was heat-treated at $130{ }^{\circ} \mathrm{C}$ for $10 \mathrm{~min}$, which confirmed the occurrence of the retro-DA reaction. The retro-DA sample was processed at $60{ }^{\circ} \mathrm{C}$ for $2 \mathrm{~h}$ to achieve the successful reconnection of DA bonds by the maleimide and furan groups, which can be demonstrated by the distinctly appearance of the $1772 \mathrm{~cm}^{-1}$ and the disappearance of $696 \mathrm{~cm}^{-1}$. Overall, the reversibility of the DA/retro-DA reaction in CPA is fully demonstrated based

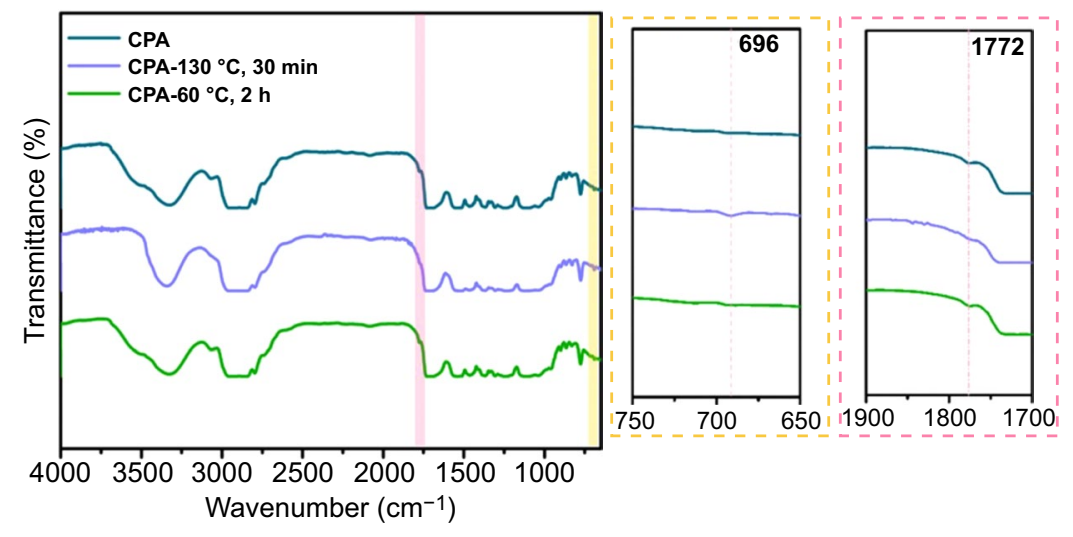

Fig. 8 FTIR spectra of initial CPA, CPA-130 ${ }^{\circ} \mathrm{C} 30 \mathrm{~min}$ (refer the initial CPA after heating at $130{ }^{\circ} \mathrm{C}$ for $30 \mathrm{~min}$, retro-DA) and CPA-60 ${ }^{\circ} \mathrm{C} 2 \mathrm{~h}$ (means the CPA-130 ${ }^{\circ} \mathrm{C} 30$ min continue to place at $60{ }^{\circ} \mathrm{C}$ for $2 \mathrm{~h}$ to re-crosslinked due to DA reaction) 
on thermal stimulation. Further, the healing behavior of the CG@CPA composite was systematically investigated.

The OM with a heat stage was used to record healing process of the CG@CPA-7. Firstly, an irregular crack with $\sim 83 \mu \mathrm{m}$ width was produced on the CG@CPA-7 by a blade. And then, the damaged composite was placed on the heating stage and heated from room temperature to $130{ }^{\circ} \mathrm{C}$ with a heating rate of $10{ }^{\circ} \mathrm{C} \mathrm{min}{ }^{-1}$. As exhibited in Fig. 9a-f, the crack shrinks slightly as the temperature arrives at $120{ }^{\circ} \mathrm{C}$ and almost diminished when the temperature maintains at $130{ }^{\circ} \mathrm{C}$ for $1 \mathrm{~min}$. Ultimately, the crack closed completely at $130{ }^{\circ} \mathrm{C}$ for $5 \mathrm{~min}$. More clearly, the SEM was used to observe the healing effect as shown in Fig. $9 \mathrm{~g}-\mathrm{i}$. It is seen that the cracks of the sample were completely repaired with only minor scratches left, proving that the crack in CG@CPA composite can be healed quickly and completely due to the presence of DA bonds inside the system.
Further, the healing mechanism of the CG@CPA composite based on the DA bonds is analyzed, as shown in Fig. 10. The damaged CG@CPA sample undergoes heat treatment at $130{ }^{\circ} \mathrm{C}$ for $5 \mathrm{~min}$. It is aim to guarantee that the molecular chain of CG@CPA composite to temporarily split into lower molecular weight substances via retroDA reactions, thereby causing viscous movement of the cleaved fragments and the involved CNT/GO networks at the injured section to glue the broken sections together again. After the disappearance of cracks, the sample is maintained at $60{ }^{\circ} \mathrm{C}$ for $2 \mathrm{~h}$, making sure the reconstruction of the DA bonds through DA reactions by the major dissociative maleimide and furan moieties. Finally, the cleaved molecular chains are re-cross-linked and the broken conductive networks are re-built, forming an intact CG@CPA composite with original mechanical and EMI shielding properties.
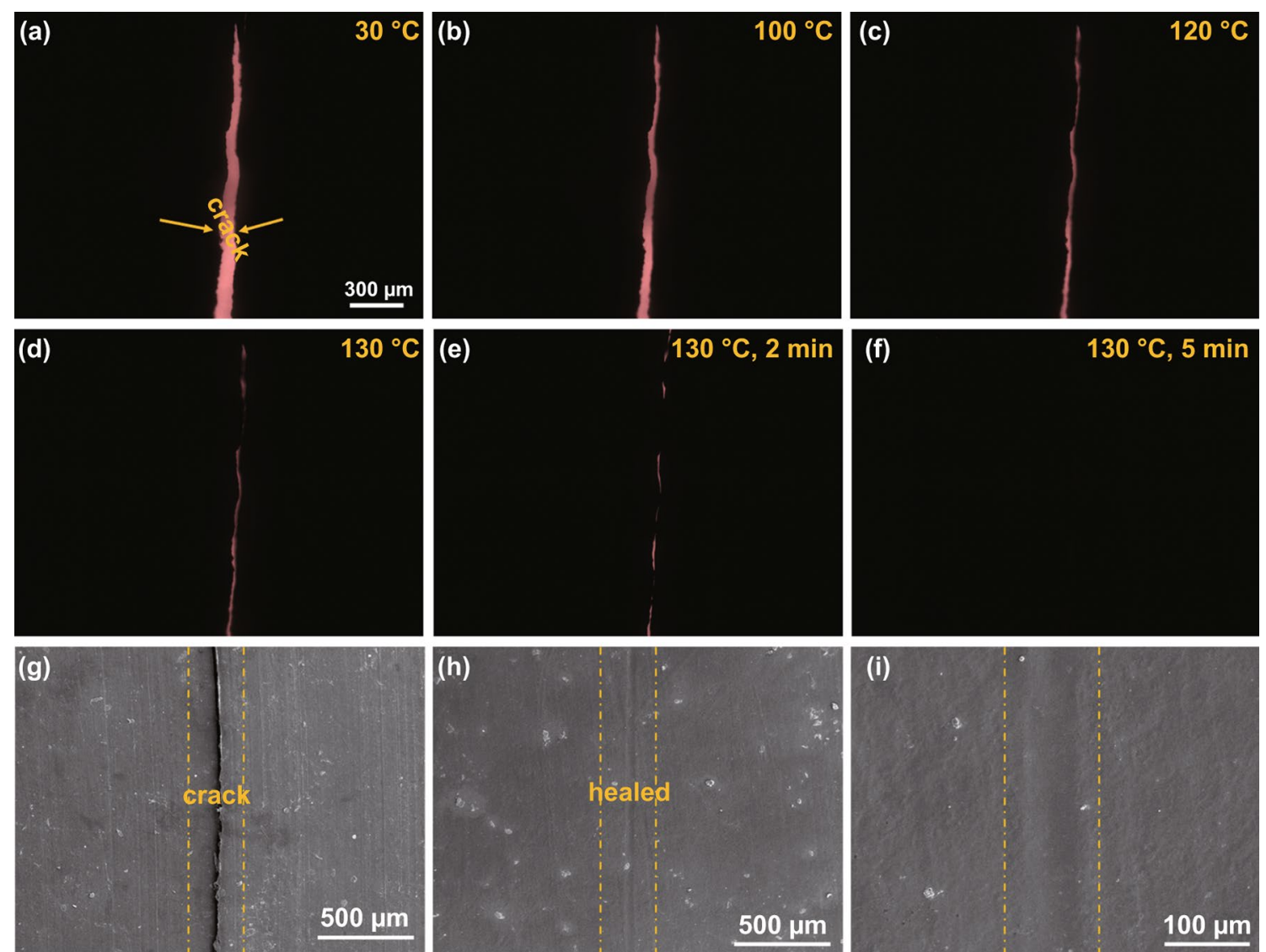

Fig. 9 a-f OM images of the healing process at different temperatures of the crack (the composite is black, thus the transparent part $<$ red $>$ is the location of the crack) on the CG@CPA-7.g-i SEM images of the surface of the CG@CPA-7 before and after healed 


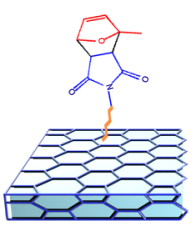

Broken

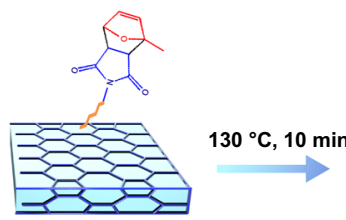

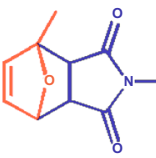

Heating

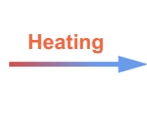

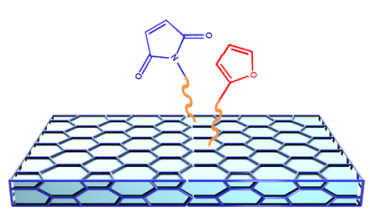

Contact

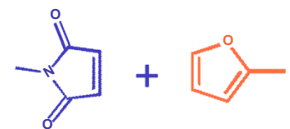

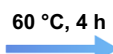

Healed

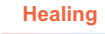

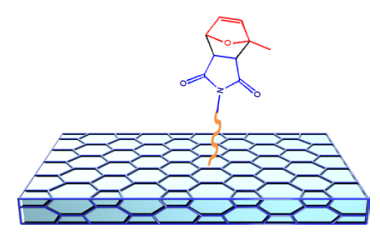

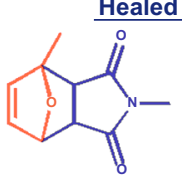

Fig. 10 Healing mechanism of the CG@CPA composite based on the DA bonds

\section{Conclusions}

A healable and durable EMI shielding composite was innovatively designed by introducing the CNT/GO hybrid onto a healable cationic waterborne polyurethane (CPA) via electrostatic assembly. The continuous segregated conduction network is formed with the CNT/GO hybrid that selectively distributes in the interfaces of CPA matrix, supplying outstanding EMI shielding performance. Additionally, the composite can be healed effectively on suffering the external mechanical stimulus due to the DA bonds in the CPA molecular chain. The EMI SE of CG@CPA10 could attain to $52.7 \mathrm{~dB}$ and thermal-driven healed to $47.3 \mathrm{~dB}$ even undergo three cutting/healing cycles. Specifically, the interfaces interaction between the CPA and CNT/GO hybrid is enhanced by the electrostatic attraction, achieving excellent mechanical properties of the CG@CPA composite. For instance, CG@CPA-3 exhibits high stress of $\sim 43.1 \mathrm{MPa}$ and high EB of $\sim 626 \%$. And the mechanical properties can also be repaired with high healing efficiency of $95 \%$ even after three recovery cycles. This novel CG@CPA composite with stable and superb EMI shielding performance provides a convenient strategy for designing advanced electrical devices.

Acknowledgements The authors gratefully acknowledge the financial support from the National Natural Science Foundation of China (Grant Nos. 51973142, 51721091, 21878194), and the National Key Research and Development Program of China (2018YFB0704200), and the funds of the State Key Laboratory of Solidification Processing (Northwestern Polytechnical University) (SKLSP201918).

Open Access This article is licensed under a Creative Commons Attribution 4.0 International License, which permits use, sharing, adaptation, distribution and reproduction in any medium or format, as long as you give appropriate credit to the original author(s) and the source, provide a link to the Creative Commons licence, and indicate if changes were made. The images or other third party material in this article are included in the article's Creative Commons licence, unless indicated otherwise in a credit line to the material. If material is not included in the article's Creative Commons licence and your intended use is not permitted by statutory regulation or exceeds the permitted use, you will need to obtain permission directly from the copyright holder. To view a copy of this licence, visit http://creativecommons.org/licenses/by/4.0/.

Supplementary Information The online version contains supplementary material available at https://doi.org/10.1007/ s40820-021-00693-5.

\section{References}

1. Y.T. Xu, Y. Wang, C.G. Zhou, W.J. Sun, K. Dai et al., An electrically conductive polymer composite with a co-continuous segregated structure for enhanced mechanical performance. J. Mater. Chem. C 8(33), 11546-11554 (2020). https://doi.org/ 10.1039/d0tc02265a

2. Y. Yao, S. Jin, H. Zou, L. Li, X. Ma et al., Polymer-based lightweight materials for electromagnetic interference shielding: a review. J. Mater. Sci. 56(11), 6549-6580 (2021). https://doi. org/10.1007/s10853-020-05635-x

3. J. Kruželák, A. Kvasničáková, K. Hložeková, I. Hudec, Progress in polymers and polymer composites used as efficient materials for EMI shielding. Nanoscale Adv. 3(1), 123-172 (2021). https://doi.org/10.1039/d0na00760a

4. H. Abbasi, M. Antunes, J.I. Velasco, Recent advances in carbon-based polymer nanocomposites for electromagnetic interference shielding. Prog. Mater. Sci. 103, 319-373 (2019). https://doi.org/10.1016/j.pmatsci.2019.02.003

5. C. Wang, V. Murugadoss, J. Kong, Z. He, X. Mai et al., Overview of carbon nanostructures and nanocomposites for electromagnetic wave shielding. Carbon 140, 696-733 (2018). https://doi.org/10.1016/j.carbon.2018.09.006

6. S. Sankaran, K. Deshmukh, M.B. Ahamed, S.K. Khadheer Pasha, Recent advances in electromagnetic interference 
shielding properties of metal and carbon filler reinforced flexible polymer composites: a review. Compos. Part A 114, 49-71 (2018). https://doi.org/10.1016/j.compositesa.2018.08. 006

7. W.C. Yu, T. Wang, Y.H. Liu, Z.G. Wang, L. Xu et al., Superior and highly absorbed electromagnetic interference shielding performance achieved by designing the reflection-absorptionintegrated shielding compartment with conductive wall and lossy core. Chem. Eng. J. 393, 124644 (2020). https://doi.org/ 10.1016/j.cej.2020.124644

8. D. Feng, Q. Wang, D. Xu, P. Liu, Microwave assisted sinter molding of polyetherimide/carbon nanotubes composites with segregated structure for high-performance EMI shielding applications. Compos. Sci. Technol. 182, 107753 (2019). https://doi.org/10.1016/j.compscitech.2019.107753

9. L.C. Jia, C.G. Zhou, W.J. Sun, L. Xu, D.X. Yan et al., Waterbased conductive ink for highly efficient electromagnetic interference shielding coating. Chem. Eng. J. 384, 123368 (2020). https://doi.org/10.1016/j.cej.2019.123368

10. J. Zhang, H. Li, T. Xu, J. Wu, S. Zhou et al., Homogeneous silver nanoparticles decorating $3 \mathrm{D}$ carbon nanotube sponges as flexible high-performance electromagnetic shielding composite materials. Carbon 165, 404-411 (2020). https://doi.org/ 10.1016/j.carbon.2020.04.043

11. S. Zhu, C. Xing, F. Wu, X. Zuo, Y. Zhang et al., Cake-like flexible carbon nanotubes/graphene composite prepared via a facile method for high-performance electromagnetic interference shielding. Carbon 145, 259-265 (2019). https://doi. org/10.1016/j.carbon.2019.01.030

12. D. Lu, Z. Mo, B. Liang, L. Yang, Z. He et al., Flexible, lightweight carbon nanotube sponges and composites for highperformance electromagnetic interference shielding. Carbon 133, 457-463 (2018). https://doi.org/10.1016/j.carbon.2018. 03.061

13. Z.H. Zhou, Y. Liang, H.D. Huang, L. Li, B. Yang et al., Structuring dense three-dimensional sheet-like skeleton networks in biomass-derived carbon aerogels for efficient electromagnetic interference shielding. Carbon 152, 316-324 (2019). https://doi.org/10.1016/j.carbon.2019.06.027

14. J. Chen, X. Liao, W. Xiao, J. Yang, Q. Jiang et al., Facile and green method to structure ultralow-threshold and lightweight polystyrene/MWCNT composites with segregated conductive networks for efficient electromagnetic interference shielding. ACS Sustain. Chem. Eng. 7(11), 9904-9915 (2019). https://doi.org/10.1021/acssuschemeng.9b00678

15. Y.F. Liu, L.M. Feng, Y.F. Chen, Y.D. Shi, X.D. Chen et al., Segregated polypropylene/cross-linked poly(ethylene-co1-octene)/multi-walled carbon nanotube nanocomposites with low percolation threshold and dominated negative temperature coefficient effect: towards electromagnetic interference shielding and thermistors. Compos. Sci. Technol. 159, 152-161 (2018). https://doi.org/10.1016/j.compscitech. 2018.02.041

16. X.H. Tang, Y. Tang, Y. Wang, Y.X. Weng, M. Wang, Interfacial metallization in segregated poly (lactic acid)/poly ( $\varepsilon$-caprolactone)/multi-walled carbon nanotubes composites for enhancing electromagnetic interference shielding. Compos. Part A 139, 106116 (2020). https://doi.org/10.1016/j. compositesa.2020.106116

17. J.H. Cai, J. Li, X.D. Chen, M. Wang, Multifunctional polydimethylsiloxane foam with multi-walled carbon nanotube and thermo-expandable microsphere for temperature sensing, microwave shielding and piezoresistive sensor. Chem. Eng. J. 393, 124805 (2020). https://doi.org/10.1016/j.cej. 2020.124805

18. M. Wang, X.H. Tang, J.H. Cai, H. Wu, J.B. Shen et al., Construction, mechanism and prospective of conductive polymer composites with multiple interfaces for electromagnetic interference shielding: a review. Carbon 177, 377-402 (2021). https://doi.org/10.1016/j.carbon.2021.02.047

19. W.C. Yu, G.Q. Zhang, Y.H. Liu, L. Xu, D.X. Yan et al., Selective electromagnetic interference shielding performance and superior mechanical strength of conductive polymer composites with oriented segregated conductive networks. Chem. Eng. J. 373, 556-564 (2019). https://doi. org/10.1016/j.cej.2019.05.074

20. L. Xu, X.P. Zhang, C.H. Cui, P.G. Ren, D.X. Yan et al., Enhanced mechanical performance of segregated carbon nanotube/poly(iactic acid) composite for efficient electromagnetic interference shielding. Ind. Eng. Chem. Res. 58(11), 44544461 (2019). https://doi.org/10.1021/acs.iecr.8b05764

21. H.Y. Wu, Y.P. Zhang, L.C. Jia, D.X. Yan, J.F. Gao et al., Injection molded segregated carbon nanotube/polypropylene composite for efficient electromagnetic interference shielding. Ind. Eng. Chem. Res. 57(37), 12378-12385 (2018). https://doi.org/10.1021/acs.iecr.8b02293

22. L.C. Jia, D.X. Yan, X. Jiang, H. Pang, J.F. Gao et al., Synergistic effect of graphite and carbon nanotubes on improved electromagnetic interference shielding performance in segregated composites. Ind. Eng. Chem. Res. 57(35), 1192911938 (2018). https://doi.org/10.1021/acs.iecr.8b03238

23. S. Utrera-Barrios, R. Verdejo, M.A. López-Manchado, M. Hernández Santana, Evolution of self-healing elastomers, from extrinsic to combined intrinsic mechanisms: a review. Mater Horiz 7, 2882-2902 (2020). https://doi.org/10.1039/ d0mh00535e

24. T.P. Huynh, P. Sonar, H. Haick, Advanced materials for use in soft self-healing devices. Adv. Mater. 29(19), 1604973 (2017). https://doi.org/10.1002/adma.201604973

25. H.J. Sim, D.W. Lee, H. Kim, Y. Jang, G.M. Spinks et al., Self-healing graphene oxide-based composite for electromagnetic interference shielding. Carbon 155, 499-505 (2019). https://doi.org/10.1016/j.carbon.2019.08.073

26. H.J. Sim, H. Kim, Y. Jang, G.M. Spinks, S. Gambhir et al., Self-healing electrode with high electrical conductivity and mechanical strength for artificial electronic skin. ACS Appl. Mater. Interfaces 11(49), 46026-46033 (2019). https://doi. org/10.1021/acsami.9b10100

27. A.V. Menon, G. Madras, S. Bose, Light weight, ultrathin, and "thermally-clickable" self-healing MWNT patch as electromagnetic interference suppressor. Chem. Eng. J. 366, 72-82 (2019). https://doi.org/10.1016/j.cej.2019.02.086 
28. T. Wang, W.C. Yu, C.G. Zhou, W.J. Sun, Y.P. Zhang et al., Self-healing and flexible carbon nanotube/polyurethane composite for efficient electromagnetic interference shielding. Compos. Part-B 193, 108015 (2020). https://doi.org/10. 1016/j.compositesb.2020.108015

29. A.V. Menon, B. Choudhury, G. Madras, S. Bose, 'Trigger-free' self-healable electromagnetic shielding material assisted by co-doped graphene nanostructures. Chem. Eng. J. 382, 122816 (2020). https://doi.org/10.1016/j.cej.2019. 122816

30. W. Yang, B. Shao, T. Liu, Y. Zhang, R. Huang et al., Robust and mechanically and electrically self-healing hydrogel for efficient electromagnetic interference shielding. ACS Appl. Mater. Interfaces 10(9), 8245-8257 (2018). https://doi.org/10. 1021/acsami.7b18700

31. G. Li, P. Xiao, S. Hou, Y. Huang, Rapid and efficient polymer/ graphene based multichannel self-healing material via DielsAlder reaction. Carbon 147, 398-407 (2019). https://doi.org/ 10.1016/j.carbon.2019.03.021

32. T. Wang, W.C. Yu, W.J. Sun, L.C. Jia, J.F. Gao et al., Healable polyurethane/carbon nanotube composite with segregated structure for efficient electromagnetic interference shielding. Compos. Sci. Technol. 200, 108446 (2020). https://doi.org/10. 1016/j.compscitech.2020.108446

33. S. Shin, J.T. Ault, J. Feng, P.B. Warren, H.A. Stone, Low-cost zeta potentiometry using solute gradients. Adv. Mater. 29(30), 1701516 (2017). https://doi.org/10.1002/adma.201701516

34. Y.J. Kwon, Y. Kim, H. Jeon, S. Cho, W. Lee et al., Graphene/ carbon nanotube hybrid as a multi-functional interfacial reinforcement for carbon fiber-reinforced composites. Compos. Part-B 122, 23-30 (2017). https://doi.org/10.1016/j.compo sitesb.2017.04.005

35. L. Tian, M.J. Meziani, F. Lu, C.Y. Kong, L. Cao et al., Graphene oxides for homogeneous dispersion of carbon nanotubes. ACS Appl. Mater. Interfaces 2(11), 3217-3222 (2010). https://doi.org/10.1021/am100687n

36. G.M. Weng, J. Li, M. Alhabeb, C. Karpovich, H. Wang et al., Layer-by-layer assembly of cross-functional semi-transparent MXene-carbon nanotubes composite films for next-generation electromagnetic interference shielding. Adv. Funct. Mater. 28(44), 1803360 (2018). https://doi.org/10.1002/adfm.20180 3360

37. W.T. Cao, F.F. Chen, Y.J. Zhu, Y.G. Zhang, Y.Y. Jiang et al., Binary strengthening and toughening of MXene/cellulose nanofiber composite paper with nacre-inspired structure and superior electromagnetic interference shielding properties. ACS Nano 12(5), 4583-4593 (2018). https://doi.org/10.1021/ acsnano.8b00997

38. J. Liu, H.B. Zhang, R. Sun, Y. Liu, Z. Liu et al., Hydrophobic, flexible, and lightweight MXene foams for high-performance electromagnetic-interference shielding. Adv. Mater. 29(38), 1702367 (2017). https://doi.org/10.1002/adma.201702367

39. L.X. Liu, W. Chen, H.B. Zhang, Q.W. Wang, F. Guan et al., Flexible and multifunctional silk textiles with biomimetic leaf-like MXene/silver nanowire nanostructures for electromagnetic interference shielding, humidity monitoring, and self-derived hydrophobicity. Adv. Funct. Mater. 29(44), 1905197 (2019). https://doi.org/10.1002/adfm.201905197

40. R. Liu, M. Miao, Y. Li, J. Zhang, S. Cao et al., Ultrathin biomimetic polymeric $\mathrm{TI}_{3} \mathrm{C}_{2} \mathrm{~T}_{\mathrm{x}}$ MXene composite films for electromagnetic interference shielding. ACS Appl. Mater. Interfaces 10(51), 44787-44795 (2018). https://doi.org/10.1021/ acsami.8b18347

41. L.C. Jia, K.Q. Ding, R.J. Ma, H.L. Wang, W.J. Sun et al., Highly conductive and machine-washable textiles for efficient electromagnetic interference shielding. Adv. Mater. Technol. 4(2), 1800503 (2019). https://doi.org/10.1002/admt.20180 0503

42. R. Sun, H.B. Zhang, J. Liu, X. Xie, R. Yang et al., Highly conductive transition metal carbide/carbonitride(MXene)@ polystyrene nanocomposites fabricated by electrostatic assembly for highly efficient electromagnetic interference shielding. Adv. Funct. Mater. 27(45), 1702807 (2017). https://doi.org/10. 1002/adfm.201702807

43. S. Pande, A. Chaudhary, D. Patel, B.P. Singh, R.B. Mathur, Mechanical and electrical properties of multiwall carbon nanotube/polycarbonate composites for electrostatic discharge and electromagnetic interference shielding applications. RSC Adv. 4(27), 13839 (2014). https://doi.org/10.1039/c3ra47387b

44. M. Arjmand, T. Apperley, M. Okoniewski, U. Sundararaj, Comparative study of electromagnetic interference shielding properties of injection molded versus compression molded multi-walled carbon nanotube/polystyrene composites. Carbon 50(14), 5126-5134 (2012). https://doi.org/10.1016/j.carbon. 2012.06.053

45. T. Kuang, L. Chang, F. Chen, Y. Sheng, D. Fu et al., Facile preparation of lightweight high-strength biodegradable polymer/multi-walled carbon nanotubes nanocomposite foams for electromagnetic interference shielding. Carbon 105, 305-313 (2016). https://doi.org/10.1016/j.carbon.2016.04.052

46. M. Arjmand, M. Mahmoodi, G.A. Gelves, S. Park, U. Sundararaj, Electrical and electromagnetic interference shielding properties of flow-induced oriented carbon nanotubes in polycarbonate. Carbon 49(11), 3430-3440 (2011). https://doi.org/ 10.1016/j.carbon.2011.04.039

47. Z. Liu, G. Bai, Y. Huang, Y. Ma, F. Du et al., Reflection and absorption contributions to the electromagnetic interference shielding of single-walled carbon nanotube/polyurethane composites. Carbon 45(4), 821-827 (2007). https://doi.org/ 10.1016/j.carbon.2006.11.020

48. Y. Huang, N. Li, Y. Ma, D. Feng, F. Li et al., The influence of single-walled carbon nanotube structure on the electromagnetic interference shielding efficiency of its epoxy composites. Carbon 45(8), 1614-1621 (2007). https://doi.org/10.1016/j. carbon.2007.04.016

49. N.C. Das, Y. Liu, K. Yang, W. Peng, S. Maiti et al., Singlewalled carbon nanotube/poly(methyl methacrylate) composites for electromagnetic interference shielding. Polym. Eng. Sci. 49(8), 1627-1634 (2009). https://doi.org/10.1002/pen.21384

50. Y.L. Yang, M.C. Gupta, Novel carbon nanotube-polystyrene foam composites for electromagnetic interference shielding. 
Nano Lett. 5(11), 2131-2134 (2005). https://doi.org/10.1021/ n1051375r

51. N. Li, Y. Huang, F. Du, X.B. He, X. Lin et al., Electromagnetic interference (EMI) shielding of single-walled carbon nanotube epoxy composites. Nano Lett. 6(6), 1141-1145 (2006). https:// doi.org/10.1021/n10602589

52. H. Wang, K. Zheng, X. Zhang, T. Du, C. Xiao et al., Segregated poly(vinylidene fluoride)/MWCNTs composites for high-performance electromagnetic interference shielding. Compos. Part-A 90, 606-613 (2016). https://doi.org/10.1016/j. compositesa.2016.08.030

53. H. Duan, Y. Xu, D.X. Yan, Y. Yang, G. Zhao et al., Ultrahigh molecular weight polyethylene composites with segregated nickel conductive network for highly efficient electromagnetic interference shielding. Mater. Lett. 209, 353-356 (2017). https://doi.org/10.1016/j.matlet.2017.08.053

54. H. Li, D. Yuan, P. Li, C. He, High conductive and mechanical robust carbon nanotubes/waterborne polyurethane composite films for efficient electromagnetic interference shielding. Compos. Part-A 121, 411-417 (2019). https://doi.org/10. 1016/j.compositesa.2019.04.003

55. H.Y. Wu, L.C. Jia, D.X. Yan, J.F. Gao, X.P. Zhang et al., Simultaneously improved electromagnetic interference shielding and mechanical performance of segregated carbon nanotube/polypropylene composite via solid phase molding.
Compos. Sci. Technol. 156, 87-94 (2018). https://doi.org/10. 1016/j.compscitech.2017.12.027

56. T. Tran-Quang, N.E. Lee, Recent progress on stretchable electronic devices with intrinsically stretchable components. Adv. Mater. 29(3), 1603167 (2017). https://doi.org/10.1002/adma. 201603167

57. X. Dai, Y. Du, J. Yang, D. Wang, J. Gu et al., Recoverable and self-healing electromagnetic wave absorbing check tor nanocomposites. Compos. Sci. Technol. 174, 27-32 (2019). https:// doi.org/10.1016/j.compscitech.2019.02.018

58. J. Li, G. Zhang, R. Sun, C.-P. Wong, A covalently cross-linked reduced functionalized graphene oxide/polyurethane composite based on diels-alder chemistry and its potential application in healable flexible electronics. J. Mater. Chem. C 5(1), 220-228 (2017). https://doi.org/10.1039/c6tc04715g

59. N. Tiwari, F. Ho, A. Ankit, N. Mathews, A rapid low temperature self-healable polymeric composite for flexible electronic devices. J. Mater. Chem. A 6(43), 21428-21434 (2018). https://doi.org/10.1039/c8ta08328b

60. Y. Fang, X. Du, Y. Jiang, Z. Du, P. Pan et al., Thermal-driven self-healing and recyclable waterborne polyurethane films based on reversible covalent interaction. ACS Sustain. Chem. Eng. 6(11), 14490-14500 (2018). https://doi.org/10.1021/ acssuschemeng.8b03151 